\title{
PERANG DINGIN DAN IMPLIKASINYA TERHADAP SISTEM POLITIK INTERNASIONAL DALAM TINJAUAN HIGH POLITICS
}

Cite as

Luerdi, Luerdi, \& Faruki, Ahmad. (2017). Perang Dingin dan Implikasinya Terhadap Sistem Politik Internasional dalam Tinjauan High Politics. International society, 4(1), 1-12.

https://doi.org/10.5281/zenodo.5830890 


\title{
Perang Dingin dan Implikasinya terhadap Sistem Politik Internasional dalam Tinjauan High Politics
}

\author{
LUERDI DAN AHMAD FARUKI \\ Universitas Abdurrab
}

\begin{abstract}
This paper aims to describe the Cold War with its implications to the system of international politics in high politics contexts. High politics, which has been the realists' interest, is one of the issues much discussed especially regarding the Cold War as the periode of which has provided many examples to international relations scholars. This paper applies the historical approach, relying on the information refering to recorded past events to describe the focus of what is presented. This paper shows that the Cold War was brought by the two super powers to many geographical areas in many forms of crisis, that then enabled to affect the international political system in term of politics, security and sovereignty.
\end{abstract}

Keywords: Cold War, high politics, implications, international political system.

\section{Pendahuluan}

Istilah Cold War pertama kali digunakan oleh Bernard Baruch dan Walter Lippman dari Amerika Serikat pada tahun 1947, yang merupakan ketegangan antara dua kekuatan besar yang bersaing dan berebut pengaruh setelah berakhirnya Perang Dunia II, yaitu Amerika Serikat dengan ideologi Liberalisme-Demokrasi dan Uni Soviet dengan ideologi Komunisme, dimulai dari tahun 1947-1991. Ketegangan ini tidak hanya membawa dampak pada ke-dua negara tersebut, tapi juga negara-negara lain yang terlibat dalam blok pimpinan AS (Blok Barat) dan blok pimpinan Uni Soviet (Blok Timur). Persaingan yang terjadi meliputi berbagai bidang seperti politik, ideologi, militer dan pertahanan, ekonomi, sosial-budaya dan teknologi ruang angkasa.

Perang Dingin dipicu oleh keinginan Presiden AS, Harry S.Truman dalam konferensi Potsdam (1945) agar diselenggarakan pemilu yang bebas di seluruh Eropa Timur pasca kalahnya koalisi Jerman-Italia-Jepang dalam Perang Dunia II. ${ }^{1}$ Namun, pimpinan Uni Soviet, Stalin, menolak tegas rencana tersebut karena adanya kekhawatiran negara-negara Eropa Timur hasil pemilu yang bebas akan memusuhi Komunisme dan Uni Soviet. Perbedaan pandangan ini dianggap sebagai faktor kunci terjadinya Perang Dingin. Perbedaan pandangan ini kemudian diikuti dengan pembagian Jerman menjadi dua negara, yaitu Jerman Barat yang berada dalam kubu AS dan Jerman Timur berada dalam kubu Uni Soviet.

Perang Dingin berakhir ditandai dengan runtuhnya tembok Berlin pada 1989 dan bersatunya Jerman Barat dan Jerman Timur pada 1990. Kemudian diikuti dengan peristiwa bubarnya Uni Soviet pada 1991 dan mundurnya Mikhail Gorbachev sebagai pemimpin Uni Soviet. Sebelumnya, Gorbachev memperkenalkan kebijakan glasnost (keterbukaan) pada tahun 1985 dan perestroika (rekonstruksi/reorganisasi) pada tahun 1987. Kebijakan ini mengakibatkan gelombang revolusi di Uni Soviet dan negara-negara satelitnya yang kemudian mengakhiri kedigdayaan Uni Soviet.

Selain itu, komitmen antara kedua negara super power tersebut melalui pertemuan di Malta (1989) dan Washington (1990) untuk bekerjasama di masa depan juga dianggap sebagai tanda berakhirnya Perang Dingin. Kedua pertemuan tersebut menghasilkan perjanjian pada akhir 1990 di mana dilakukannya pengurangan dan pembatasan senjata

\footnotetext{
${ }^{1}$ Fredrick L.Schuman., International Politics: The Western State System and the World Community, Sixth Edition, USA: McGrew-Hill Company, Inc, 1958, hal. 485-486.
} 
konvensional secara drastis di Eropa dan disepakatinya pakta non-agresi antara NATO and Organisasi Keamanan Warsawa. ${ }^{2}$ Perang Dingin memberikan pengaruh yang besar terhadap perubahan sistem politik internasional dan implikasinya khususnya berkaiatan dengan high politics. High politics meliputi isu-isu yang berkaitan dengan politik keamanan dan pertahanan, kedaulatan dan juga militer.

\section{Perang Dingin}

Persaingan dan ketegangan antara AS dan Uni Soviet begitu jelas selama periode Perang Dingin. Walaupun secara langsung kedua negara tidak terlibat dalam perperangan face to face, tapi perilaku kedua negara dengan kebijakan luar negerinya mencerminkan situasi persaingan dan ketegangan yang terjadi di antara kedua kekuatan tersebut. Bahkan berbagai krisis yang terjadi di berbagai negara, AS dan Uni Soviet beserta sekutu mereka terlibat dalam krisis tersebut demi mempertahankan dan memperebutkan kepentingan mereka.

AS berpegang teguh pada teori domino, yaitu apabila suatu negara jatuh ke tangan atau pengaruh komunisme, maka komunisme akan merambat ke negara-negara tetangganya. Sehingga AS memiliki kepentingan untuk mencegah penyebaran Komunisme. Di lain pihak, Uni Soviet memiliki konsep keamanan yang hanya bisa dibangun dengan sekutu sejati. Sekutu sejati bagi Uni Soviet adalah negara-negara yang berideologikan komunisme.

Perang Dingin dapat dilihat dari krisis atau perang di berbagai belahan dunia. Selain itu, Perang Dingin juga telah mampu membelah suatu wilayah negara menjadi dua bagian yang saling bermusuhan berdasarkan ideologi liberalisme dan komunisme.

\section{Blokade Berlin 1948-1949}

Pasca kalahnya kekuatan Nazi Jerman di akhir perang Dunia II, pengelolaan kota Berlin dibagi menjadi beberapa zona. Uni Soviet menguasai sebagian besar wilayah Berlin yaitu bagian tengah dan timur. Sedangkan AS, Inggris dan Perancis menguasai wilayah Barat. $^{3}$ Uni Soviet berinisiatif melakukan blokade terhadap Berlin karena semakin meruncingnya persaingan ideologi dengan AS. Selain itu, Uni Soviet bermaksud mencegah penyebaran pengaruh AS di wilayah Berlin bagian tengah dan timur dan menguasai Berlin secara keseluruhan.

Blokade Berlin dianggap sebagai krisis kemanusiaan pertama dalam Perang Dingin antara Amerika Serikat dan Uni Soviet. Krisis ini juga dianggap sebagai krisis internasional pertama yang menyebabkan banyak korban jiwa setelah berakhirnya Perang Dunia II. Uni Soviet memberlakukan larangan keluar-masuk Berlin pada Juni 1948 sebagai respon terhadap diberlakukannya reformasi ekonomi dan Deutsche Mark sebagai valuta baru oleh AS dan sekutunya (Inggris dan Perancis) di Jerman Barat.4

AS memasok kebutuhan logistik warga Berlin Barat melalui jalar udara. Jembatan udara yang dibuat oleh AS berhasil memasok kebutuhan logistik warga Berlin Barat. Uni Soviet hanya memberlakukan blokada Berlin selama satu tahun karena pada Mei 1949, Uni Soviet mencabut blokade ini. Namun, dua tahun kemudian Uni Soviet membangun rangkaian tembok pembatas yang membagi kota Berlin, yang juga menjadi pemisah teritori antara Jerman Barat dan Jerman Timur.

\section{Invasi Teluk Babi (Playa Giron) 1961}

Invasi Teluk Babi merupakan sebuah pendaratan yang direncanakan dan didanai oleh Amerika Serikat dan dilakukan oleh orang-orang Kuba di pembuangan di Kuba Barat

\footnotetext{
${ }^{2}$ Richard W. Mansbach dan Kirsten L.Rafferty., Pengantar Politik Global, Edisi Terjemahan, Bandung:Penerbit Nusa Media, 201, hal.229-230.

3 'Uni Soviet Blokade Berlin', <dunia.news.viva.co.id>, [diakses 29 Oktober 2015].

${ }^{4}$ Ibid.,
} 
Daya untuk menggulingkan pemerintahan Fidel Castro. Peristiwa ini menandai klimaks tindakan anti-Kuba oleh AS. AS takut revolusi yang dilakukan Castro akan meningkatkan kepercayaan diri dan mendorong kelompok-kelompok anti-AS di negara-negara lain di Amerika latin untuk melakukan hal yang sama.

Dengan jatuhnya Kuba ke tangan Castro dengan sistem Komunisme-nya, Uni Soviet semakin meningkatkan pengaruh Komunisme dan politik di negara-negara Amerika Latin. ${ }^{5}$ Uni Soviet giat melakukan diplomasi dan kerjasama dengan pemerintahan di negara-negara Amerika Latin yang anti-AS. Selain itu, Uni Soviet juga menjalin komunikasi politik yang intens dengan partai-partai Komunis di Amerika Latin.

Ketegangan AS-Kuba telah tumbuh sejak Castro menggulingkan rezim diktator militer sayap kanan Jenderal Fulgencio Batista yang didukung AS pada 1959. AS di bawah pemerintahan Eisenhower dan Kennedy telah menilai bahwa pergeseran Castro kepada Uni Soviet tidak bisa diterima dan karena itu mereka berusaha menggulingkannya dengan memanfaatkan kelompok anti-Castro dan anti-Soviet.

Invasi ini mengalami kegagalan total dan ternyata menjadi noda internasional bagi pemerintahan AS. Sebaliknya, pemerintahan Fidel Castro menganggap tindakan yang dilakukan menghadapi pemberontak yang didukung oleh AS ini sebagai perang melawan para bandit. Ketegangan AS-Uni Soviet semakin tajam setelah usaha invasi tersebut. Bahkan, invansi Teluk Babi ini kemudian menyalut krisis nuklir antara AS dan Uni Soviet.

\section{Krisis Missil Kuba 1962}

Invasi Teluk Babi yang disponsori oleh AS mengakibatkan kemarahan Kuba dan Uni Soviet. Kedua negara mengecam tindakan AS tersebut. Walaupun invasi tersebut mengalami kegagalan, Kuba dan Uni Soviet meningkatkan kewaspaan terhadap berbagai tindakan Amerika di masa yang akan datang yang dapat mengancam eksistensi kedua negara tersebut.

Uni Soviet memutuskan untuk membangun pangkalan missil balistik di Kuba. AS mengecam pembangunan tersebut karena berpotensi mengancam keamanan nasionalnya. Secara geografis, pangkalan missil balistik yang terletak di laut Karibia tersebut dekat dengan AS.

Uni Soviet tidak menghiraukan keberatan AS dan tetap mengirimkan peralatan militernya secara terus menerus, termasuk senjata missil balistik berhulu ledak nuklir. AS merasa terancam karena rudal-rudal yang diletakkan di Kuba diarahkan ke AS. AS akhirnya memblokade Kuba untuk mencegah pasokan militer Uni Soviet ke Kuba dan memberlakukan status siaga tinggi.

Uni Soviet sebenarnya juga terancam dengan keberadaan pangkalan missil Balistik AS yang telah ditempatkan di wilayah Turki yang berdekatan dengan wilayahnya. Posisi rudal-rudal balistik AS telah diarahkan ke Uni Soviet.

AS memiliki pilihan untuk menghancurkan pangkalan rudal missil Uni Soviet di Kuba melalui serangan udara ataupun serangan darat yang cepat. Namun, dengan berbagai pertimbangan seperti sisi moral dan dampak yang begitu besar, aksi militer tidak digunakan mengingat Uni Soviet tidak akan tinggal diam, dan akan melakukan balasan terhadap AS. ${ }^{6}$

Ke-dua negara sama-sama meningkatkan kewaspadaan terhadap ancaman serangan dari salah satu pihak yang datang dari pangkalan missil balistiknya. Ke-dua negara juga siap siaga untuk meluncurkan rudal-rudal berhulu ledak nuklir. Serangan tersebut dapat menjadi perang dunia III atau perang nuklir 'jarak dekat' yang akan

\footnotetext{
${ }^{5}$ Anthony T.Bouscaren, Is the Cold War over?;A New Look at Communist Imperialism, USA:The Capitol Hill Press, 1973, hal. 236.

${ }^{6}$ Dominic Tierney, 'Pearl Harbor in Reverse;Moral Analogies in the Cuban Missile Crisis', dalam Journal of Cold War Studies, Harvard University, Vol. 9, Issue 3 (Summer,2007), hal. 61, <http://www.fas.harvard.edu>, [diakses 31 Oktober 2015].
} 
mengakibatkan hancurnya kedua negara tersebut. Ketegangan antara AS dan Uni Soviet seperti inilah yang kemudian dikenal dengan krisis missil Kuba.

Krisis Missil Kuba berakhir pada tanggal 28 Oktober 1962 dengan diadakannya kesepakatan antara AS dan Uni Soviet. Uni Soviet melalui Perdana Menterinya ketika itu (Nikita Khrushchev) sepakat untuk melucuti persenjataan missilnya yang ditempatkan di Kuba dan AS dibawah pemerintahan Presiden John F.Kennendy juga sepakat untuk melucuti persenjataan nuklirnya yang telah ditempatkan di Turki. AS juga berjanji untuk tidak akan menyerang Kuba. ${ }^{7}$

\section{Perang Korea 1950-1953}

Perang Korea melibatkan AS dan PBB dalam membantu Korea Selatan mengusir tentara Korea Utara keluar dari wilayah Korea Selatan. Perang ini disebut juga dengan istilah proxy war (perang yang dimandatkan) karena perang ini melibatkan PBB bersama negera-negara lainnya seperti Kanada, Inggris dan lainnya. Dewan Keamanan PBB mengeluarkan resolusi untuk merespon tindakan Korea Utara yang telah melanggar hukum internasional. ${ }^{8}$ Di AS, perang ini disebut dengan aksi Polisional karena dilakukan dibawah bendera PBB dan keterlibatan AS tidak mesti mendapatkan persetujuan kongres.

Perang Korea disulut oleh invasi besar-besaran yang dilakukan oleh Korea Utara untuk menguasai Korea Selatan pada tahun 1950. Kekuatan Korea Selatan tidak sebanding dengan kekuatan Korea Utara. Serangan tersebut mengundang intervensi AS dan PBB untuk memukul mundur Korea Utara yang didukung oleh RRC dan Uni Soviet.

Di lapangan, Uni Soviet tidak terlibat dalam mengerahkan pasukannya. Namun, tentara rezim Komunis Korea Utara yang menginvasi Korea Selatan dilatih oleh Uni Soviet. Uni Soviet juga terlibat dalam melakukan aksi spionase dan pasokan perlengkapan militer untuk tentara Korea Utara. ${ }^{9}$

Konflik antara Korea Selatan dan Korea Utara sebenarnya telah terjadi semenjak Korea dibagi dua oleh AS dan Uni Soviet. Baik Korea Selatan yang berideologi LiberalismeDemokrasi dan Korea Utara yang berideologi Komunisme sama-sama berkeinginan menyatukan Korea namun di bawah naungan ideologi masing-masing. Baik AS dan Uni Soviet juga berkepentingan terhadap eksistensi kedua negara tersebut.

Perang Korea berakhir dengan diadakannya perjanjian gancatan senjata antara AS, RRC, dan Korea Utara. Korea Selatan menolak untuk menandatangani gencatan senjata tersebut, namun Presiden Korea Selatan kala itu (Syngman Rhee) berjanji akan menghormati kesepakatan gencatan senjata tersebut. Secara resmi Perang Korea sebenarnya belum berakhir sampai sa'at ini.

\section{Perang Vietnam 1959-1975}

Konflik antara Vietnam Utara dan Vietnam Selatan telah dimulai sejak Vietnam dibelah menjadi dua oleh Perancis pada tahun 1954 melalui sebuah konferensi yang diadakan di Jenewa, Swiss. ${ }^{10}$ Uni Soviet sempat mengusulkan kepada PBB agar Vietnam Utara diterima sebagai anggota PBB pada tahun 1957. Namun, AS memveto usulan tersebut dikarenakan Vietnam Utara berhaluan Komunis.

Keterlibatan AS dalam perang Vietnam mendukung Vietnam Selatan memberikan kerugian besar di pihak AS. Karena berada di bawah desakan masyarakatnya sendiri, AS di bawah kepemimpinan Richard M. Nixon segera merubah kebijakan politik AS di Vietnam dari semula 'bagaimana caranya memenangkan perang' menjadi 'bagaimana caranya mundur dari gelanggang tanpa kehilangan muka.'

\footnotetext{
${ }^{7}$ Anthony T.Bouscaren, Op.Cit., hal. 236.

8 Charles L.Robertson., International Politics Since World War II;A Short History, 2nd Edition, USA: John Wiley \& Sons. Inc., 1975, hal. 114.

${ }^{9}$ Anthony T.Bouscaren, Op.Cit., hal.158.

${ }^{10}$ Richard W. Mansbach dan Kirsten L.Rafferty., Op.Cit., hal. 214.
} 
Atas dasar desakan internasional, AS menandatangani perjanjian perdamaian Paris pada 27 Januari 1973. Perjanjian ini memuat hal bahwa AS akan segera menarik bantuan langsungnya di Selatan secara berangsur, batas teritori Utara dan Selatan dikukuhkan ulang dan pemilihan umum akan segera dilangsungkan untuk menyelesaikan masalah Utara-Selatan. Namun, perjanjian ini ditentang oleh Vietnam Selatan karena Vietnam Selatan masih membutuhkan bantuan AS.

AS sebenarnya masih enggan melaksanakan isi perjanjian tersebut sampai krisis minyak dunia terjadi pada tahun yang sama. AS terancam mengalami kebangkrutan dan akhirnya menarik seluruh pasukan dan menghentikan bantuan ke Vietnam Selatan. Tanpa bantuan dan kekuatan finansial dan militer dari AS, Vietnam Utara dengan mudah melumpuhkan dan mengabil alih Vietnam Selatan.

\section{Perang Afganistan 1979-1989}

Uni Soviet melakukan invasi terhadap Afganistan pada tahun 1979. Kebijakan invansi Uni Soviet ini didasarkan oleh keyakinan atas kemampuan Uni Soviet dalam mentransformasi Afganistan, menstabilkan pemerintahan dari perang sipil dan meraih pengakuan internasional terhadap rezim Komunis di Afganistan. ${ }^{11}$ Uni Soviet ingin memepertahankan kekuasaan Partai Rakyat Demokratik Afganistan yang berhaluan Marxisme sehingga Afganistan tetap menjadi sekutu Uni Soviet.

AS terlibat secara tidak langsung dalam mengusir Uni Soviet keluar dari Afganistan. Keterlibatan AS diwujudkan dalam bentuk bantuan finansial, persenjataan, pelatihan militer dan spionase kepada para kelompok pemberontak rezim Afganistan dan antiKomunisme. Uni Soviet secara resmi meninggalkan Afganistan pada Februari 1989.

\section{Krisis-krisis Lainnya (RRC-Taiwan, Israel-Mesir, India-Pakistan)}

Perang Dingin antara AS dan Uni Soviet juga dapat dilihat dari berbagai krisis lain selain yang disebutkan di atas, seperti krisis RRC-Taiwan. Keberhasilan revolusi Komunis di Cina tidak terlepas dari dukungan Uni Soviet, sedangkan eksistensi Taiwan sebagai sebuah negara baru mendapat dukungan dari Amerika Serikat. Selama periode Perang Dingin, AS dan Uni Soviet juga terlibat dalam membantu berbagai revolusi, pemberontakan dan kudeta terhadap rezim penguasa di beberapa negara.

Dalam perkembangannya, praktik persaingan AS dan Uni Soviet di era Perang Dingin tidak selalu diwujudkan dalam bentuk dukungan pada pihak berdasarkan ideologi Komunisme atau Demokrasi-Liberalisme. Kedua negara tersebut bisa saja mendukung suatu pihak yang sedang berkonflik, selagi dianggap dapat menjadi kawan strategis. Sebagai contoh adalah perang Israel-Mesir dan India-Pakistan.

Dalam perang antara Israel dan Mesir, Amerika Serikat memberikan dukungan kepada Israel, sedangkan Uni Soviet memberikan dukungan kepada Mesir. Dan dalam perang antara India dan Pakistan, AS memberikan bantuan kepada Pakistan, sedang Uni Soviet memberikan bantuan kepada India.

\section{Implikasi Perang Dingin}

Perang Dingin yang terjadi antara AS dan Uni Soviet memberikan implikasi yang luas dalam sistem politik internasional. Ketegangan dan persaingan ideologi dan politik antara kedua negara tersebut mampu menarik negara-negara lain masuk dalam lingkaran pengaruh mereka. Walaupun AS dan Uni Soviet tidak berhadapan dalam kondisi perang secara langsung selama periode tersebut, nyatanya Perang Dingin mengakibatkan perubahan geopolitik wilayah, konflik bersenjata berdarah yang menyebabkan korban jiwa, konflik internal dan perpecahan berbagai negara di dunia, sampai hampir terjadinya

\footnotetext{
${ }^{11}$ Artemy Kalinovsky,'Decision-Making and the Soviet War in Afghanistan: From Intervention to Withdrawal', dalam Journal of Cold War Studies, Harvard University, Vol.11, Issue 4, (Fall, 2009), hal. 47, <http://www.fas.harvard.edu $>$, [diakses 31 Oktober 2015].
} 
perang nuklir.

AS dan Uni Soviet berupaya untuk memperluas pengaruhnya ke berbagai negara, tidak hanya di daratan Eropa, tapi juga di Asia, Afrika dan Amerika Latin. AS giat melakukan propaganda anti-Soviet dan begitu pula dengan Uni Soviet aktif melakukan propaganda anti-Amerika dan sekutunya. Kedua negara sama-sama memiliki pandangan akan perlunya memperluas pengaruh ideologi dan politik ke berbagai belahan dunia.

AS menerapkan politik pembendungan (cointainment policy) untuk mencegah penyebaran pengaruh Uni Soviet dan Komunisme ke seluruh dunia. Politik containment didasarkan pada asumsi bahwa Uni Soviet berupaya melakukan ekspansi tanpa batas (limitless expansion) dan kebijakan Uni Soviet ini diinspirasikan oleh pandangan Komunisme tentang konflik yang tak terhindarkan antara Kapitalisme dan Sosialisme. ${ }^{12}$ Kebijakan di atas telah menciptakan konflik AS-Uni Soviet di berbagai negara. AS tidak rela bila suatu negara jatuh seutuhnya pada pengaruh Komunisme.

Persaingan dalam penyebaran pengaruh kemudian berimplikasi pada peningkatan kemampuan militer dan pertahanan kedua negara, termasuk persenjataan nuklir. Berbagai aliansi strategis juga dibentuk oleh AS dan Uni Soviet. Selain aliansi yang memihak pada poros-poros kekuatan AS dan Uni Soviet, juga terbentuk aliansi yang yang berada di luar kekuatan tersebut.

\section{Pengembangan dan Perlombaan Persenjataan Nuklir}

Persaingan ideologi yang terjadi antara AS dan Uni Soviet juga mengakibatkan perubahan cara pandang terhadap keamanan nasional. Kedua negara berkeyakinan keamanan nasional mesti diprioritaskan demi keberlangsungan negara. Serangan dari kekuatan lawan bisa saja terjadi karena baik AS dan Uni Soviet sama-sama berambisi untuk menjadi yang paling kuat dan berpengaruh.

Konflik tidak langsung antara AS dan Uni Soviet di berbagai belahan dunia bisa saja mengarah pada konflik secara langsung. Dengan demikian, kedua negara merasa perlu untuk meningkatkan kekuatan militer dan pertahanannya, tidak hanya kekuatan militer konvensional tapi juga kekuatan persenjataan nuklir.

Bagi AS, nuklir merupakan sarana penangkalan terhadap ancaman nuklir Uni Soviet, sekaligus untuk mengurangi ketegangan dengan Uni Soviet. Walaupun penggunaan senjata nuklir dalam konfrontasi fisik dengan Uni Soviet adalah sangat tidak mungkin dilakukan, strategi pengembangan nuklir masih tetap dilakukan untuk menciptakan penangkalan yang berkelanjutan. ${ }^{13}$

Kedua negara sama-sama yakin bahwa nuklir menjadi jaminan bagi keamanan negara dari serangan dari luar. Selain itu, pemilikan senjata nuklir menjadi cara yang paling logis bagi AS dan Uni Soviet untuk mengimbangi kekuatan masing-masing. AS tidak ingin kekuatan persenjataan nuklirnya tertinggal jauh dari Uni Soviet, dan begitu juga Uni Soviet.

Dengan keyakinan tersebut, AS dan Uni Soviet menggiatkan dan meningkatkan pengembangan senjata nuklir. Senjata nuklir dianggap mampu untuk mengancam lawan sekaligus menjaga keamanan nasional. Pemilikan senjata nuklir juga dijadikan daya tarik oleh kedua negara untuk mendapatkan dukungan dan kepercayaan negara-negara lain untuk bergabung dengan aliansi AS atau aliansi Uni Soviet. Situasi perlombaan kekuatan nuklir antara AS-Uni Soviet ini tidak hanya ditujukan untuk menciptakan balance of power, namun juga balance of terror. ${ }^{14}$

Pengembangan senjata nuklir yang dilakukan oleh AS dan Uni Soviet berubah

${ }^{12}$ Charles L.Robertson, Op.Cit., hal. 69.

${ }^{13}$ William Burr, 'The Nixon Administration, the Horror Strategy, and the Search for Limited Nuclear Options, 1969-1972', dalam Journal of Cold War Studies, Harvard University, Vol. 7, Issue 3, (Summer, 2005), hal. 3435, <http://www.fas.harvard.edu>, [diakses 13 Oktober 2015].

${ }^{14}$ Joseph Frankel., International Politics; Conflict and Harmony, London: Cox and Wyman, Ltd., 1969, hal. 78. 
menjadi perlombaan kekuatan persenjataan nuklir. Pemilikan senjata nuklir menjadi prestise atau show of force atas kekuatan militer kedua negara. Perlombaan senjata nuklir ini lah yang akhirnya menjadi kekhawatiran dunia bahwa Perang Dingin akan menjadi perang nuklir, yang jauh lebih dahsyat ketimbang Perang Dunia II. Contoh nyata perlombaan persenjataan nuklir antara AS dan Uni Soviet yang hampir mengarah pada perang nuklir adalah krisis missil Kuba.

\section{Terbentuknya Tatanan Dunia yang Bipolar}

Akhir Perang Dunia II menghasilkan dua kekuatan besar yaitu AS dan Uni Soviet. Walaupun AS dan Uni Soviet, bersama Inggris dan Perancis, berada dalam satu koalisi menentang dan mengalahkan kekuatan Nazi Jerman, kedua negara tidak bisa menghasilkan pandangan yang sama dalam mengelola Eropa pasca Perang Dunia II. Perbedaan ideologi dan kepentingan mempersulit AS dan Uni Soviet untuk mencapai kata sepakat dalam melakukan konstruksi Eropa. Bahkan, perbedaan pandangan dari kedua belah pihak semakin tajam dan memaksa kedua belah pihak berjalan pada keyakinan masing-masing. ${ }^{15}$

AS berupaya menjadikan negara-negara Eropa Barat sebagai sekutu membendung pengaruh Komunisme Uni Soviet. Sedangkan Uni Soviet menanamkan power-nya di Eropa Timur. Bagi Uni Soviet, negara-negara yang beridiologikan Komunisme lah yang hanya bisa menjadi sekutu sejati sehingga Uni Soviet memaksa dan mendukung revolusi negaranegara di Eropa Timur. Dengan kondisi seperti ini Eropa terbelah menjadi dua blok, yaitu Blok Barat yang dipimpin oleh AS dan Blok Timur yang dipimpin oleh Uni Soviet.

Tatanan dunia pasca Perang Dunia II jelas menghasilkan bipolar system, di mana hanya ada dua negara super power yang mampu mempengaruhi sistem politik, ekonomi dan militer di berbagai negara. Pihak Washington dan Moscow saling berebut pengaruh dan menunjukkan superioritas atas satu sama lain, tidak hanya menyebarkan pengaruhnya di daratan Eropa tapi juga di benua lainnya untuk memperluas aliansi. ${ }^{16}$

\section{Terbentuknya Aliansi Militer Strategis}

Persaingan AS dan Uni Soviet selama periode Perang Dingin mempengaruhi pandangan kedua negara tentang keamanan, militer dan pertahanan. Persaingan tersebut dapat dilihat dengan dibentuknya berbagai blok atau pakta pertahanan yang dipelopori oleh kedua negara super power tersebut.

Pembentukan berbagai pakta pertahanan tersebut berdasarkan kepentingan geostrategis di berbagai kawasan yang berbeda. Artinya, medan persaingan antara AS dan Uni Soviet tidak lagi berpusat di Eropa saja, tapi juga di kawasan Asia dan Pasifik. Namun, pakta pertahanan tersebut memiliki tujuan yang sama sebagai aliansi militer strategis untuk menjaga keamanan kedua negara beserta negara-negara yang bergabung dalam keanggotaannya. Beberapa pakta pertahanan yang terbentuk selama periode perang dingin diantaranya adalah NATO, SEATO, CENTO, ANZUS dan Pakta Warsawa.

\section{NATO}

North Atlantic Treaty Organization (NATO) terbentuk setelah ditandatanganinya North Atlantic Treaty pada 04 April 1949. Tujuan utama pembentukan pakta ini adalah untuk mengawal kebebasan dan keamanan negara-negara anggota baik dengan sarana politik maupun militer. ${ }^{17}$ Secara politis, NATO mempromosikan nilai-nilai demokrasi dan mendorong konsultasi dan kerjasama berkenaan dengan isu-isu pertahanan dan keamanan untuk membangun kepercayaan, dalam jangka panjang untuk pencegahan konflik. Sedangkan secara militer, NATO berkomitmen untuk penyelesaian konflik secara

\footnotetext{
${ }^{15}$ Anthony T.Bouscaren, Op.Cit., hal. 121-122.

16 Joseph Frankel., Op.Cit., hal. 77-78.

17 'North Atlantic Treaty Organization', <www.nato.int>, [diakses 31 Oktober 2015]
} 
damai. Jika usaha diplomasi gagal, NATO memiliki kapasitas mengambil tindakan atau melakukan operasi crisis-management secara sendirian, dibawah mandat PBB atau bekerjasama dengan negara-negara lain. ${ }^{18}$

NATO menerapkan prinsip collective defense di mana setiap anggota NATO sepakat untuk saling melindungi terhadap serangan yang datang dari luar keanggotaan NATO. ${ }^{19}$ Serangan terhadap salah satu negara anggota NATO dianggap sebagai serangan terhadap negara-negara anggota NATO lainnya. Pembentukan pakta pertahanan ini disponsori oleh AS untuk membendung ancaman kekuatan militer Uni Soviet pada awalnya. Namun, dalam perjalanannya Perancis menyatakan menarik diri dari keanggotan NATO. ${ }^{20}$

Selama Perang Dingin, kekuatan NATO yang berpusat di Eropa mampu membendung sebagian ambisi Uni Soviet untuk mengejar proyek-proyek Komunisme dan memperluas aliansi militernya, bahkan sampai di Asia Tengah. ${ }^{21}$ NATO selalu mengikuti perkembangan kebijakan luar negeri Uni Soviet untuk menentukan respon secara politik dan militer. NATO juga terlibat dalam mengirimkan kekuatan militernya pada Perang Korea dibawah mandat PBB untuk memukul mundur Korea Utara.

\section{SEATO}

South-east Asia Treaty Organization (SEATO) dibentuk setelah ditandatanganinya pakta Manila (Manila Pact) pada September 1954 yang bermarkas di Bangkok. Pembentukan SEATO merupakan respon atas kekalahan dan penarikan diri Perancis dari Indochina (Vietnam). ${ }^{22}$ Pakta pertahanan ini dibentuk karena adanya kekhawatiran penyebaran Komunisme di wilayah tersebut. Selain itu, SEATO dibentuk untuk membendung kekuatan Komunisme di Asia Tenggara. Kekuatan Barat khususnya AS berkepentingan dalam pembentukan pakta pertahanan ini.

Walaupun SEATO dibentuk untuk melindungi Asia Tenggara agar tidak jatuh ke komunisme, secara geografis tidak semua anggota SEATO merupakan negara-negara yang berada dalam kawasan Asia Tenggara. Pembentukan SEATO ditandatangani oleh Australia, Inggris, Perancis, Selandia Baru, Pakistan, Filipina, Thailand, dan AS. ${ }^{23}$ Sedangkan Malaysia, Indonesia, dan India menolak untuk bergabung dengan pakta pertahanan ini. Selain untuk membendung komunisme, motivasi keterlibatan negaranegara non-blok Barat, khususnya Pakistan, dalam keanggotaan SEATO adalah untuk medapatkan paket bantuan pertahanan dan militer dari AS. ${ }^{24}$

SEATO melibatkan diri dalam berbagai konflik internasional dan salah satunya adalah dalam Perang Vietnam. Namun, dalam perjalanannya negara-negara yang tergabung dalam SEATO tidak selalu satu suara dalam beberapa operasi militer. Kegagalan intervensi dalam krisis Vietnam dan Laos akhirnya meruntuhkan keyakinan anggotaanggotanya terhadap eksistensi SEATO, sampai kemudian bubar pada tahun 1977.

\section{CENTO}

AS menyadari perlunya membangun aliansi pertahanan berdasarkan pertimbangan geostrategis. Pada tahun 1950-an, AS mengformulasikan pembentukan pakta pertahanan SEATO dan CENTO untuk mengamankan kawasan Asia dari ancaman komunisme. ${ }^{25}$ AS

${ }^{18}$ Ibid.,

${ }^{19}$ Ibid.,

20 Ibid.,

${ }^{21}$ Karsten Jung, 'Willing or Waning? NATO's Role in an Age of Coalitions',

$<$ http://www.worldaffairsjournal.org > , [diakses 31 Oktober 2015].

22'Treaties and alliances - NZ and the Cold War', <http://www.nzhistory.net.nz>, [diakses 31 Oktober 2015].

23 Ibid.,

${ }^{24}$ Lubna Saif, 'Pakistan and SEATO', dalam Pakistan Journal of History and Culture, Vol. XXVIII, No.2 (2007),

hal. 79, <http://www.nihcr.edu.pk>, [diakses 31 Oktober 2015].

${ }^{25}$ Mussarat Jabeen and Muhammad Saleem Mazhar, 'Security Game: SEATO and CENTO as Economic and

Military Assistance to Encircle Pakistan', dalam Pakistan Economic and Social Review, Volume 49, No.1

(Summer, 2011), hal.109, <http://pu.edu.pk>, [diakses 31 Oktober 2015]. 
menyadari Uni Soviet menjadikan kawasan Asia sebagai proyek penyebaran agendaagenda komunisme.

Central Treaty Organization (CENTO) secara khusus dibentuk pada 1955 untuk membendung Uni Soviet dan komunisme di kawasan Timur Tengah. Sebelumnya, CENTO bernama Middle East Treaty Organization (METO) dan juga dikenal dengan Baghdad Pact. Adapun negara-negara yang menandatangani pembentukan CENTO adalah Irak, Iran, Pakistan, Turki dan Inggris.

Amerika Serikat memang tidak masuk dalam pakta pertahanan ini pada awal pembentukannya. Namun, tekanan yang dilakukan AS dan janji ekonomi dan militer menjadi faktor yang penting dalam menyukseskan pembentukan CENTO. AS secara resmi baru bergabung dengan komite militer CENTO pada tahun 1958. Dalam perkembangan berikutnya, CENTO dianggap sebagai pakta pertahanan aliansi AS yang paling buruk. CENTO bubar pada tahun 1979.

\section{ANZUS}

Pakta pertahanan ANZUS dibentuk pada tahun 1951 melalui Canberra Talks dan merupakan formalisasi hubungan militer AS bersama Autralia dan Selandia Baru. ${ }^{26}$ Sebelum pembentukan pakta pertahanan ini, AS telah menjalin hubungan militer dengan kedua negara tersebut. ANZUS merupakan singkatan negara-negara inisiator pakta pertahanan ini yaitu Autralia, New Zealand dan United States.

Pembentukan ANZUS merupakan kompensasi bagi Australia dan Selandia baru atas keinginan AS melakukan normalisasi hubungan dengan Jepang pasca Perang Dunia II atau di awal-awal periode Perang Dingin. Normalisasi hubungan AS dengan Jepang juga mengarah pada recovery dan revitalisasi militer Jepang sebagai imbalan dari AS, karena AS ingin menempatkan pangkalan militernya di kepulauan Jepang. ${ }^{27}$

Bagi Australia dan Selandia Baru, Jepang masih dianggap sebagai ancaman di kawasan Pasifik sehingga membutuhkan jaminan keamanan dari AS. AS memberikan jaminan keamanan kepada Australia dan Selandia Baru dengan dibentuknya ANZUS. Seperti pakta pertahanan lainnya, ANZUS juga mengaplikasikan collective defence. Serangan terhadap salah satu anggota ANZUS akan dianggap sebagai serangan terhadap angota ANZUS lainnya.

Namun, bagi Amerika Serikat, ANZUS merupakan aliansi strategis untuk membendung penyebaran komunisme di kawasan Asia dan Pasifik. Keberadaan ANZUS dibutuhkan untuk menjaga stabilitas kawasan tersebut. Selain itu, Australia merupakan sekutu AS yang paling loyal dalam hampir setiap kebijakan luar negeri AS sehingga dapat diandalkan oleh AS. ${ }^{28}$ Salah satu keikutsertaan ANZUS dalam krisis internasional adalah dalam Perang Vietnam.

\section{Pakta Warsawa}

Setelah terbentuknya NATO pada tahun 1949, Uni Soviet menggagas pakta petahanan yang disebut Pakta Warsawa (Warsaw Pact) yang beranggotakan negara-negara Blok Timur atau komunis Eropa Timur. Pakta pertahanan ini dibentuk untuk menandingi kekuatan NATO dan melindungi keamanan Uni Soviet dan negara-negara anggotanya dari serangan luar. Secara khusus, pembentukan aliansi pertahanan ini dipicu dengan masuknya Jerman Barat ke dalam keanggotaan NATO. ${ }^{29}$

Pakta Warsawa dirancang oleh Perdana Menteri Uni Soviet (Nikita Khrushchev) dan

\footnotetext{
${ }^{26}$ Hiroyuki Umetsu, 'The Birth of ANZUS: America's Attempt to Create a Defense Linkage Between Northeast Asia and the Southwest Pacific', <http://irap.oxfordjournals.org>, [diakses 31 Oktober 2015].

27 Ibid.,

${ }^{28}$ William T.Tow, 'The Anzus Case Alliance Interests,Costs And Benefits in A 9/11 Context', dalam Australian Army Journal, Volume III, number 2, (March, 2006), hal. 28, <http://www.army.gov.au>, [diakses 31 Oktober 2015].

29 'The History of NATO and Warsaw Pact', <http://samilitaryhistory.org>, [diakses 31 Oktober 2015].
} 
secara resmi dibentuk pada tahun 1955. Pakta pertahanan ini ditandatangani oleh negaranegara Komunis Eropa Timur (kecuali Yugoslavia) seperti Uni Soviet, Albania, Bulgaria, Cekoslovakia, Jerman Timur, Hongaria, Polandia dan Rumania. ${ }^{30}$ Selain untuk melindungi diri dari ancaman luar, pembentukan pakta pertahanan ini juga dimaksudkan untuk peningkatan kerjasama pertahanan dan militer antar negara-negara anggotanya.

Latar belakang fundamental pembentukan Pakta Warsawa merupakan respon Uni Soviet terhadap remiliterisasi Jerman Barat setelah bergabung dengan NATO. ${ }^{31}$ Remiliterisasi Jerman Barat menimbulkan ketakutan dan ancaman bagi negara-negara Komunis Eropa yang merupakan sekutu Uni Soviet. Dengan keberadaan pakta pertahanan ini, Blok Barat memiliki alasan untuk tidak menyerang salah satu anggota Pakta Warsawa.

Dalam perkembangannya, seperti halnya Perancis yang menarik diri dari keanggotaan NATO, Hongaria mencoba keluar dari keanggotaan Pakta Warsawa tahun 1956. Namun, Uni Soviet melakukan invansi terhadap negara ini dengan tank dan senjata mesin. ${ }^{32}$

\section{Terbentuknya Gerakan Non-Blok (GNB)}

Munculnya AS dan Uni Soviet sebagai kekuatan baru pasca Perang Dunia II telah mampu menarik negara-negara di dunia, khususnya Eropa ke dalam Blok Barat dan Blok Timur, di mana AS dan Uni Soviet adalah pimpinannya. Namun, Perang Dingin tidak hanya berimplikasi pada terbentuknya polarisasi dua kekuatan tersebut. Kekhawatiran negaranegara dunia ketiga terhadap persaingan ideologi dan militer AS-Uni Soviet memberikan inspirasi terbentuknya kekuatan baru di luar pusaran polarisasi tersebut, yaitu Gerakan Non-blok (Non-Alligned Movement). ${ }^{33}$

Gerakan Non-Blok dibentuk setelah diadakannya konferensi Asia Afrika di Bandung, Indonesia pada tahun 1955. Gerakan Non-Blok dimotori oleh Indonesia, India, Mesir, Ghana dan Yugoslavia. Gerakan ini umumnya beranggotan negara-negara Asia, Afrika dan Amerika Latin. Selain menghindari aliansi dengan Blok Barat dan Blok Timur, gerakan ini juga bertujuan untuk menentang kolonialisme, neo-kolonialisme dan dominasi Barat. $^{34}$

Pembentukan Gerakan Non-Blok berupaya untuk membuka jalan bagi politik dunia yang independen tanpa komando dan dominasi AS dan Uni Soviet. Walau demikian, pengaruh AS dan Uni Soviet ternyata mampu mempenetrasi kebijakan negara-negara anggota GNB. Ini disebabkan negara-negara tersebut memiliki ketergantungan terhadap keberadaan kedua super power tersebut, terutama berkaitan dengan ekonomi dan militer. 35

Walaupun demikian, keberadaan GNB secara umum telah memberikan pengaruh terhadap sistem politik internasional selama periode Perang Dingin, berkaitan dengan kerjasama politik dan diplomasi. Selain itu, dunia ketika era Perang Dingin sebenarnya menjadi terbagi ke dalam tiga kelompok. Amerika Serikat memimpin Blok Barat dengan sistem politik liberalisme-demokrasi. Uni Soviet memimpin Blok Timur dengan sistem politik komunisme. Kelompok ketiga adalah negara-negara yang tidak ingin terikat pada Amerika Serikat ataupun Uni Soviet yang tergabung dalam GNB.

\section{Runtuhnya Uni Soviet dan Munculnya Negara-negara Baru.}

Perang Dingin berakhir pada tahun 1991 ditandai dengan runtuhnya Uni Soviet.

\footnotetext{
30 Ibid.,

${ }^{31}$ N.Wagner, 'NATO and the Warsaw Pact', dalam Scientia Militaria, South African Journal of Military Studies, Vol 8, Nr 4, (1978), hal. 41, <http://scientiamilitaria.journals.ac.za> [diakses 31 Oktober 2015].

32 'The History of NATO and Warsaw Pact', Op.Cit.,

33 'The Non-Aligned Movement: Description and History', <http://www.nam.gov.za>, [diakses 31 Oktober 2015].

34 Ibid.,

35 Gabor Bur, Hungarian Diplomacy and the Non-Aligned Movement in the Cold War, Budapest: Universität Wien, 2010, hal.353-354, <http://www.coldwar.hu> >, [diakses 31 Oktober 2015].
} 
Keruntuhan Uni Soviet ini mengakibatkan perubahan geopotilik di berbagai kawasan, khususnya di Eropa. Begitu pula dengan politik global di mana AS kemudian dianggap menjadi pemenang dengan ideologi liberalisme-demokrasi-nya. Sistem politik dunia yang bipolar berubah menjadi unipolar.

Uni Soviet runtuh dan terpecah menjadi beberapa negara di mana Rusia mewarisi pemerintahan dan kekuatan Uni Soviet yang masih tersisa. Sedangkan negara-negara bekas reruntuhan Uni Soviet menjadi negara-negara baru yang merdeka seperti Lithuania, Estonia, Latvia, Moldova, Belorus, Ukraina, Georgia, Armenia, Azerbaijan, Kazakhstan, Uzbekistan, Tajikistan, Turkmenistan dan Kirgistan. ${ }^{36}$ Negara-negara ini umumnya berada di kawasan Eropa Timur.

Semua negara-negara baru pecahan Uni Soviet melepaskan diri dari Komunisme sebagai akibat terjadinya pergantian rezim-rezim komunis dengan rezim-rezim demokratis. Walaupun demikian, pengaruh Rusia masih cukup besar terhadap negaranegara tersebut. Dengan keberadaan negara-negara pecahan Uni Soviet ini menambah jumlah negara-negara berkembang atau negara-negara dunia ke-tiga.

\section{Simpulan}

AS dan Uni Soviet menjadi dua kekuatan baru setelah perang Dunia II. Perbedaan pandangan dalam rekontruksi Jerman dan Eropa pasca kekalahan Nazi Jerman, berimbas pada persaingan ideologi, politik dan militer. Persaingan ini menyebabkan terjadinya polarisasi kekuatan dunia. Persaingan yang kemudian menjadi ketegangan AS-Uni Soviet tidak hanya terjadi di kawasan Eropa, tapi juga di kawasan benua lainnya. Polarisasi kekuatan dunia antara AS dan Uni Soviet tersebut mendorong terbentuknya NAM atau GNB yang menjadi aktor dalam sistem politik internasional dalam periode Perang Dingin.

Dalam konteks high politics, AS dan Uni Soviet, bersama sekutu-sekutu mereka berupaya untuk menjaga keamanan nasional atau kedaulatan dari ancaman salah satu pihak dengan membentuk aliansi-aliansi pertahanan. Kekuatan militer dan kerjasama militer menjadi pilihan rasional untuk mewujudkan hal tersebut di tengah-tengah sistem internasional yang anarkis. Namun, runtuhnya Uni Soviet memberikan konsekuensi munculnya negara-negara baru di Eropa. Keruntuhan Uni Soviet dan hadirnya AS sebagai pemenang Perang Dingin merubah peta geopolitik di berbagai negara dan kawasan di dunia.

Dengan kata lain, Perang Dingin dibawa oleh ke-dua super powers tersebut ke berbagai wilayah dunia dalam bentuk krisis-krisis dan kemudian mampu mempengaruhi sistem politik internasional dalam hal politik (munculnya polarisasi politik ideologis), keamanan (terbentuknya berbagai aliansi pertahanan strategis dan perlombaan persenjataan nuklir) dan kedaulatan negara (munculnya negara-negara berdaulat baru).

\section{REFERENSI}

\section{Buku dan jurnal}

Bouscaren, Anthony T., Is the Cold War over?; A New Look at Communist Imperialism, USA, The Capitol Hill Press,1973.

Bur, Gabor., Hungarian Diplomacy and the Non-Aligned Movement in the Cold War, Budapest, Universität Wien, 2010, <http://www.coldwar.hu >

Burr, William, 'The Nixon Administration, the Horror Strategy and the Search for Limited Nuclear Options, 1969-1972', dalam Journal of Cold War Studies, Vol.7, Issue 3, Summer 2005, <http://www.fas.harvard.edu >

Frankel, Joseph.International Politics; Conflict and Harmony, London: Cox and Wyman,Ltd., 1969.

36 Richard W. Mansbach dan Kirsten L. Rafferty., Op.Cit., hal. 231. 
Jabeen, Mussarat and Muhammad Saleem Mazhar,'Security Game: SEATO and CENTO as Economic and Military Assistance to Encircle Pakistan', dalam Pakistan Economic and Social Review,Vol. 49, No.1, Summer 2011, <http://pu.edu.pk>

Kalinovsky, Artemy, 'Decision-Making and the Soviet War in Afghanistan: From Intervention to Withdrawal', dalam Journal of Cold War Studies, Vol.11, Issue 4, Fall, 2009, <http://www.fas.harvard.edu>

Mansbach, Richard W dan Kirsten L. Rafferty., Pengantar Politik Global, Edisi Terjemahan, Bandung, Penerbit Nusa Media, 2012.

N. Wagner, 'NATO and the Warsaw Pact', dalam Scientia Militaria, South African Journal of Military Studies,Vol. 8, No. 4, 1978, <http://scientiamilitaria.journals.ac.za>

Robertson, Charles L. International Politics Since World War II; A Short History, 2nd Edition, USA: John Wiley \& Sons.Inc, 1975.

Saif, Lubna., 'Pakistan and SEATO', dalam Pakistan Journal of History and Culture, Vol. XXVIII, No.2, 2007, <http://www.nihcr.edu.pk>

Schuman, Fredrick L., International Politics; The Western State System and the World Community, Sixth Edition, USA, McGrew-Hill Company,Inc, 1958.

Tow, William T., 'The Anzus Case Alliance Interests, Costs And Benefits in A 9/11 Context', dalam Australian Army Journal ,Volume III, No. 2, March, 2006, <http://www.army.gov.au>

Tierney, Dominic,'Pearl Harbor in Reverse; Moral Analogies in the Cuban Missile Crisis', dalam Journal of Cold War Studie, Vol. 9, Issue 3, Summer, 2007, <http://www.fas.harvard.edu $>$

\section{Media internet}

Jung, Karsten.',Willing or Waning? NATO's Role in an Age of Coalitions', $<$ http://www.worldaffairsjournal.org >, (diakses 31 Oktober 2015).

Umetsu, Hiroyuki., 'The Birth of ANZUS: America's Attempt to Create a Defense Linkage Between Northeast Asia and the Southwest Pacific', $<$ http://irap.oxfordjournals.org>, (diakses 31 Oktober 2015).

'North Atlantic Treaty Organization', <www.nato.int>, (diakses 31 Oktober 2015).

'The History of NATO and Warsaw Pact', <http://samilitaryhistory.org>, (diakses 31 Oktober 2015).

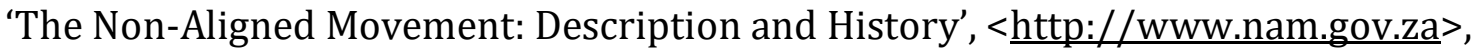
(diakses 31 Oktober 2015)

'Treaties and alliances - NZ and the Cold War', <http://www.nzhistory.net.nz>, (diakses 31 Oktober 2015)

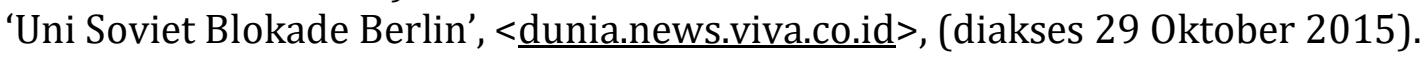

